\title{
MONITORING STRUCTURE AND REGIONAL-LEVEL DISPLACEMENTS FOR LISBON USING MULTITEMPORAL INSAR TECHNIQUES
}

\author{
Dora Roque $^{(1)}$, Daniele Perissin ${ }^{(2)}$, Ana Paula Falcão ${ }^{(3)}$, Ana Maria Fonseca ${ }^{(1)}$, Maria João Henriques ${ }^{(1)}$

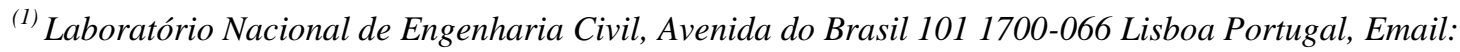 \\ droque@lnec.pt; anafonseca@lnec.pt; mjoao@lnec.pt \\ ${ }^{(2)}$ Purdue University, West Lafayette Indiana USA, Email: daniele.perissin@sarproz.com \\ ${ }^{(3)}$ Instituto Superior Técnico - Universidade de Lisboa, Avenida Rovisco Pais 1 1049-001 Lisboa Portugal, Email: \\ ana.p.falcao@tecnico.ulisboa.pt
}

\begin{abstract}
The city of Lisbon is the capital of Portugal and has been devastated by catastrophic events in the past, such as earthquakes and tsunamis. This study provides a regional analysis of displacements for the city and its neighbourhoods, between 2008 and 2010, through the application of mutitemporal InSAR techniques on Envisat ASAR images. Smaller areas with identified problems were subjected to a more refined processing. Besides, the behaviour of some key infrastructures, such as important buildings or railways, was carefully analysed in order to evaluate their safety. Subsidence was detected at the regional and small areas, in which the highest subsidence rates were verified on industrial parks or on landfills close to the river. Seasonal trends were found for the small areas, mainly related with structure thermal expansion or variations in underground water.
\end{abstract}

\section{INTRODUCTION}

Lisbon, being an important governmental, business and historical place, has 3 million people living in it and in its surroundings. The frequent and accurate monitoring of ground stability and its influence on infrastructures, such as the road network, railways, bridges and buildings is vital in order to ensure the safety of the people using them.

Lisbon is located in a region of high seismicity, due to its proximity to the joint point of the Eurasian and African tectonic plates, and has been affected by devastating earthquakes and tsunamis in the past. The largest registered event was an earthquake occurred in 1755 (Mw 8.7), which was followed by a tsunami. Some parts of the city of Lisbon were completely destroyed, namely the Downtown, as other parts suffered little damage. The outcome of the earthquake in the Downtown is often related to the soil instability in that area. The Downtown is known to be the joint point of two underground streams and the soil is composed of alluvial sediments transported from those streams. In the present days, the Downtown is still an area which requires concern about its soil stability in case a new earthquake occurs [1]. The original alluvial soil was covered with debris from the 1755 earthquake and a new building model was adopted. To prevent large damages in case of new earthquakes, the buildings were built with a wooden structure shaped like a cage and were fixed to the soil through wood stakes, referred as "Gaiolas Pombalinas". The stakes were permanently kept in the presence of underground water to be healthy. Therefore, it is to be expected that changes in the underground water influence the buildings, possibly affecting their stability. The buildings located in the Downtown nowadays are still those built after the earthquake. As the city of Lisbon has been expanding in the last decades, an increase in the terrain load due to buildings and infrastructure construction has been verified, aggravated by the construction of subway lines and groundwater extraction.

Multitemporal interferometric SAR (MTI) techniques for studying soil instability in urban environments have been largely applied $[2 ; 3 ; 4]$. This study is focused on the detailed analysis of small areas and of individual buildings and infrastructures [5;6], which is not found in the literature so often. The study also concerns the limitations of using medium resolution Envisat ASAR data for this goal and points out the advantages that are expected from the usage of the new Sentinel-1A images. This paper presents an application of multitemporal InSAR techniques to the city of Lisbon and its neighbourhood. Refined processing is performed for the Downtown area and for key infrastructures in the city, such as railways and the MEO Arena building. Some subsidence areas have been identified in previous studies [7] and are not going to be discussed in this document.

\section{STUDY AREA AND DATASET}

An area of $2000 \mathrm{~km}^{2}$ of the city of Lisbon and its surroundings was selected for performing a multitemporal InSAR analysis (Fig. 1). The study area comprises both banks of the Tagus River and the main communication ways to access the city: bridges, railways and highways. 


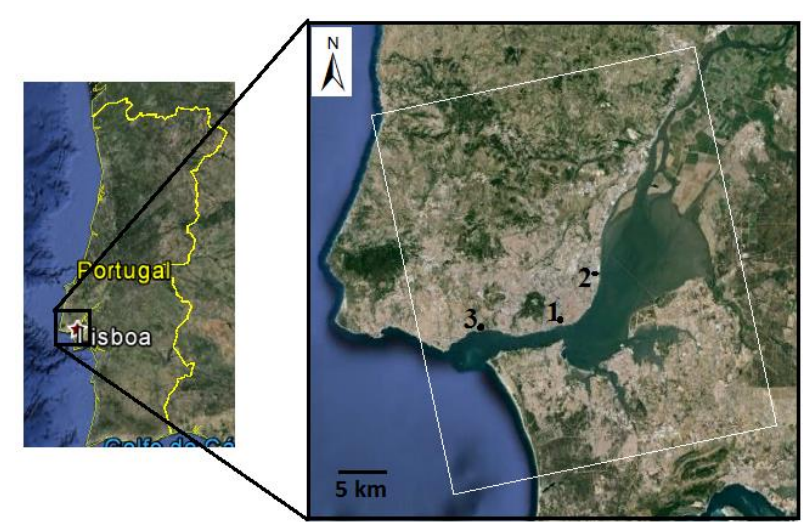

Figure 1. Regional study area and location of the smaller study areas

Refined processing with multitemporal InSAR techniques was performed for three smaller areas, in which displacement models more adequate to each case were used. The first area was the Downtown (point 1 in Fig. 1), which is a very important area in the city, as several ministries and business centres are located there. Besides, the buildings are 250 years old and the area was submitted to UNESCO's World Heritage tentative list. Currently, the National Laboratory for Civil Engineering monitors vertical displacements in a levelling line at Praça do Comércio (a large square close to the river) and a subsiding behaviour that increases with the proximity to the river was identified. The second selected area was the MEO Arena building (point 2 in Fig. 1). This building is used for shows and its larger room, the Atlântico room, has the capacity for 12500 people. It is a relatively new building, built for the World Expo that took place in Lisbon in 1998. The building presents an inner structure formed by wooden beams shaped like arches. These arches are monitored by geodetic techniques twice a year by the National Laboratory for Civil Engineering, through a network of 28 points. The observation of $3 \mathrm{D}$ displacements led to the conclusion that, as expected, the wood in the structure dilates during winter due to the increase of the air moisture. The third selected area was a segment of the railway connecting Lisbon and Cascais (point 3 in Fig. 1). Signs of instability were visually identified in the area, such as settlements, although there are not any geodetic observations available.

The dataset used in this study was composed by 19 Envisat ASAR images from an ascending track acquired every 35 days between August 2008 and May 2010. The used digital elevation model (DEM) was SRTM. The processing was performed on the software SARPROZ (www.sarproz.com), developed by Professor Daniele Perissin.

\section{METHODS}

\subsection{Regional area}

The interferometric stack of the available ASAR images was co-registered, georeferenced and a master image from July 2009 was chosen. For Atmospheric Phase Screen (APS) estimation, a set of candidate points was selected through their values of the Amplitude Stability Index. The APS values were obtained from the inversion of the residuals, when residual height and non-linear displacement values were estimated for each persistent scatterer (PS) candidate. For the PS processing, a larger number of points was selected (using a lower threshold for Amplitude Stability Index) and estimations were obtained for the residual height and linear displacements. High coherence values were obtained for the considered PSs. The APS results obtained for the regional area were used in the processing of the smaller areas.

\subsection{The Downtown}

An area of $1.5 \mathrm{~km} \mathrm{x} 1.5 \mathrm{~km}$ comprising only the Downtown area was chosen. A high number of points was selected for the processing (Fig. 2).

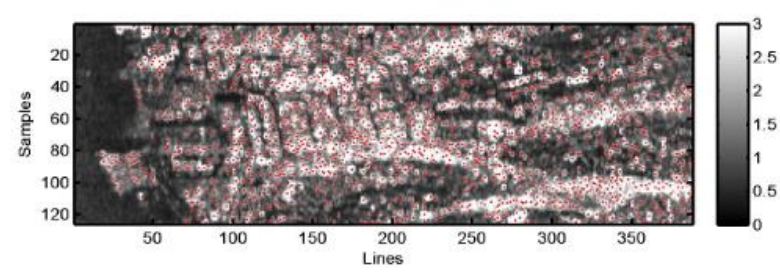

\section{Figure 2. Map of amplitude mean for the Downtown} with the possible PSs superimposed (red)

On a first approach, residual height and non-linear displacements were estimated for those points. As the obtained displacement time-series was noisy but the residual height was correctly estimated, a refinement of the results was performed. The points were reprocessed, fixing the previous values for the residual height, while both linear and seasonal trends were estimated. The points presenting temporal coherence above 0.86 were considered for further analysis.

\subsection{The MEO Arena building}

A small neighbourhood of the MEO Arena building (Fig. 3), spanning $450 \mathrm{~m} \times 700 \mathrm{~m}$, in the Eastern part of Lisbon, was selected and several candidates to PSs were identified. From the results of the geodetic measurements, it is known that the building presents seasonal behaviour. Therefore, the residual height, linear and seasonal trends were estimated for the points candidate to be PSs. The analysis was focused on the points located on the building alone and only those presenting stable amplitude time series and temporal coherence above 0.93 were considered. 


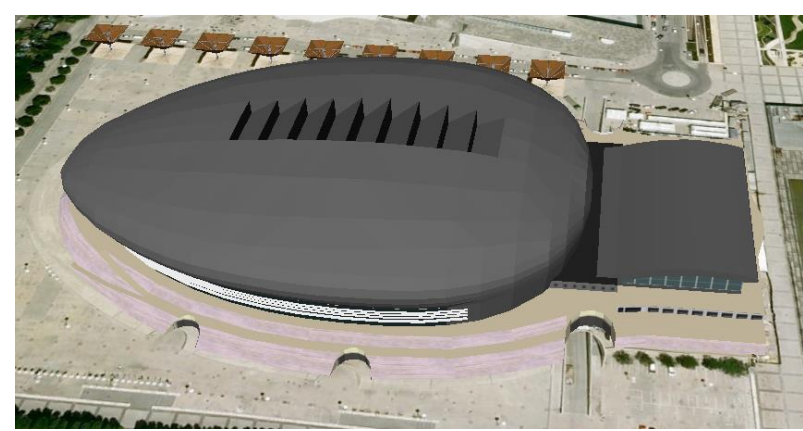

Figure 3. 3D model of the MEO Arena building (Google Earth (C)

\subsection{The railway}

A subset of around $12.5 \mathrm{~km}$ of the railway connecting Lisbon and Cascais was selected. As the railway is located close to the river, the altitude from the external DEM was used to constrain the points selected through the Amplitude Stability Index (Fig. 4).

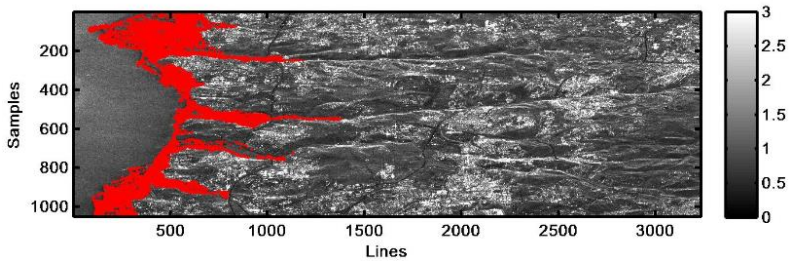

Figure 4. Candidate points (red) for the railway superimposed on the amplitude mean

The processing for this area considered the estimation of the residual height and non-linear displacements. Only points presenting temporal coherence above 0.9 were used in further analysis. In order to delete all the PSs outside the railway, the results from the multitemporal InSAR processing were analysed in QGIS. The centre of the railway was manually digitized and the PSs inside a buffer with the width of the railway were selected.

\section{RESULTS AND DISCUSSION}

\subsection{The regional area}

A large number of PSs was identified for the regional area and only those presenting temporal coherence values above 0.9 were considered, leading to a total of 2206 points available (Fig. 5). As expected, a high number of PSs was obtained for the urban areas, while only a few were found on the rural ones. A large area of the Lisbon municipality presented negative velocity values, corresponding to a subsiding behaviour. One of the largest regions presenting high subsidence rates, named Laranjeiras, has already been studied before [7] and the subsidence has been confirmed by GNSS and geometric levelling. However, the results for the remaining areas have yet to be confirmed. The largest subsidence rate was found in Póvoa de Santa Iria, a town to the north-east of Lisbon. It is an isolated PS with a velocity of $-15.1 \mathrm{~mm} / \mathrm{yr}$ located in an industrial park (Fig. 6). Previous studies detected subsidence in another industrial park located $4 \mathrm{~km}$ to the north-east of this one [7]. In that case, the subsidence was verified to be caused by underground water extraction for industrial use.

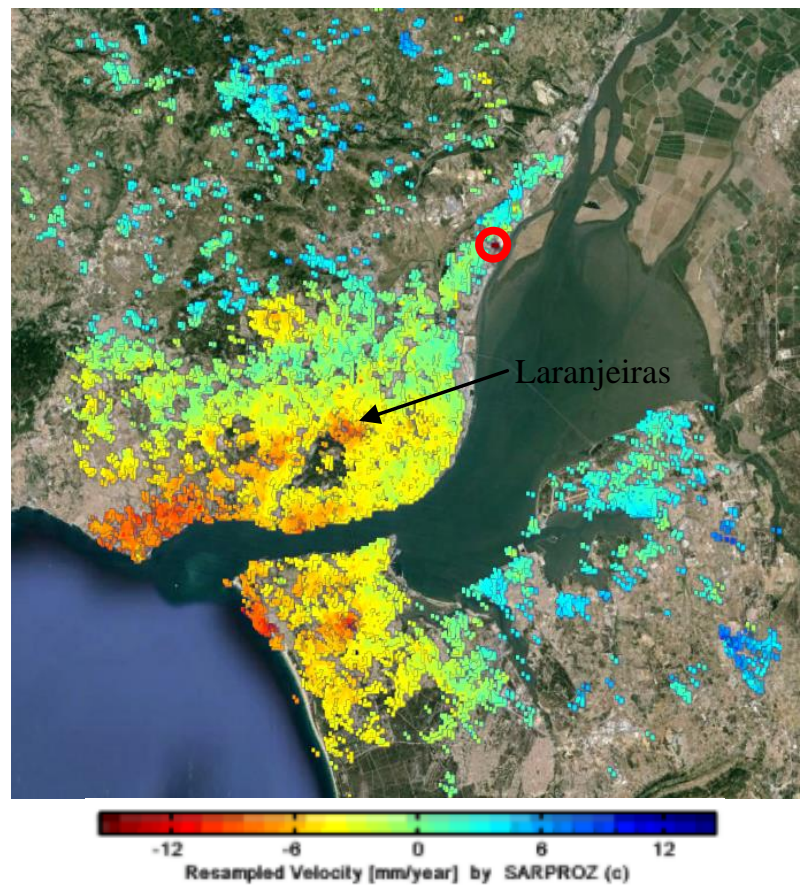

Figure 5. Linear velocity map for the regional area; Póvoa de Santa Iria in red circumference
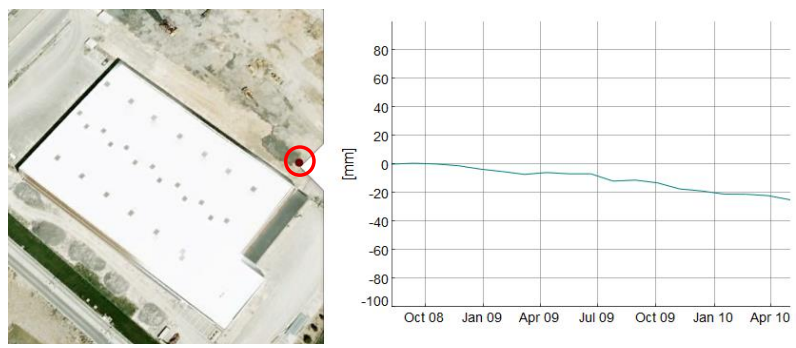

Figure 6. PS with subsidence behaviour (red circumference) and its displacement time series (right)

A refined processing was performed for the region at Póvoa de Santa Iria presenting subsidence, in which non-linear displacements were considered and a high number of PSs was achieved. Several PSs were identified having velocities that reached $-34.1 \mathrm{~mm} / \mathrm{yr}$. The area presenting the highest subsidence occupies around $0.6 \mathrm{~km}^{2}$ and includes an industrial area and saltworks. Besides, a larger area neighbouring this one also presents subsiding behaviour with lower magnitudes for greater distances to the industrial area (Fig. 7). Possible causes are still being researched. 


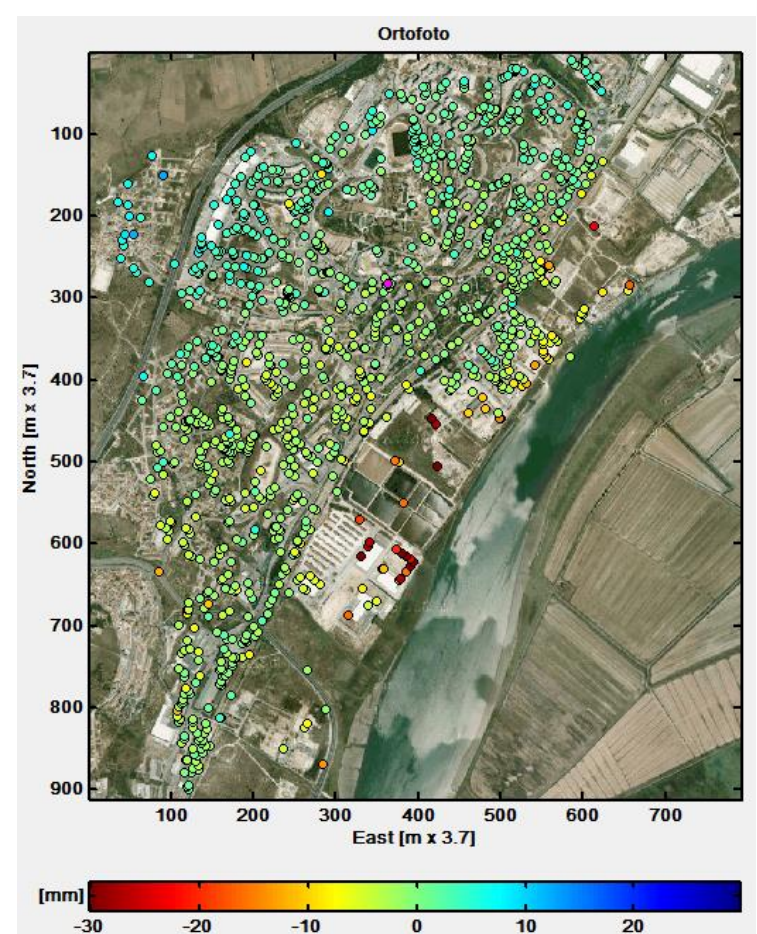

Figure 7. Cumulative displacement for PSs located in Póvoa de Santa Iria

\subsection{The Downtown}

A density of $435 \mathrm{PSs} / \mathrm{km}^{2}$ was obtained for the Downtown. The reference point is located outside the location of the underground streams that exist in the area.

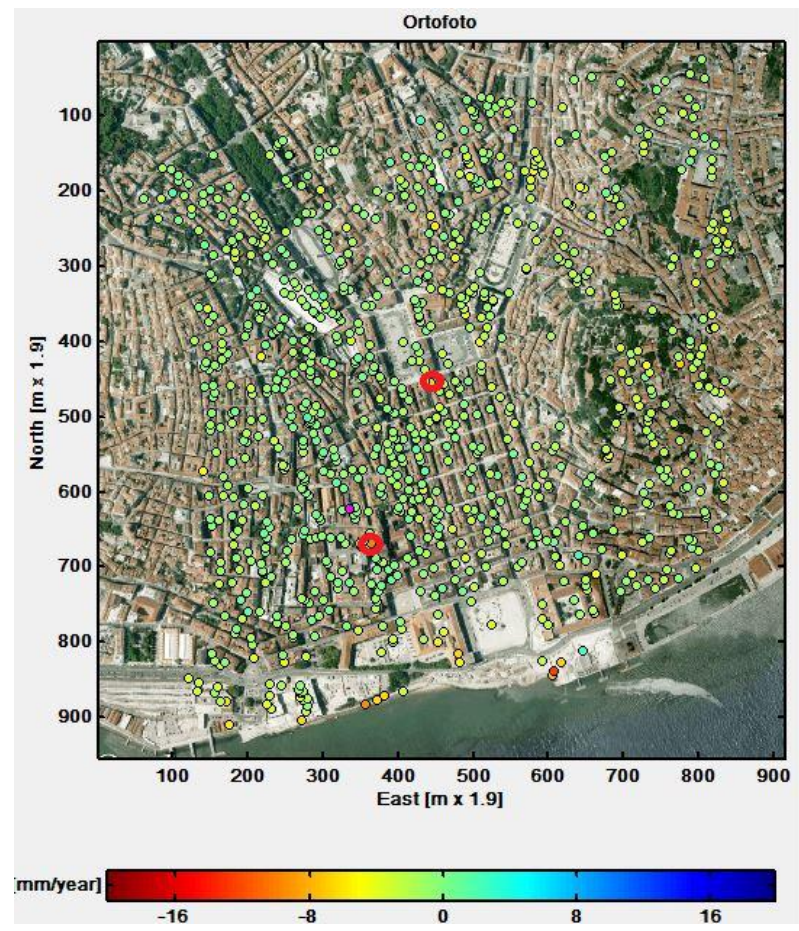

Figure 8. Linear velocity for PSs in the Downtown
The map for linear velocities shows that most of the Downtown presents a stable behaviour (Fig. 8), with velocity values close to zero. However, a subsiding trend was identified in the landfill areas close to the river, probably caused by soil compaction in these areas. PSs were detected with velocities reaching $-12.2 \mathrm{~mm} / \mathrm{yr}$ close to a recent subway line that was being built during the image acquisition time interval. There are not PSs close to the levelling line surveyed by the National Laboratory for Civil Engineering at Praça do Comércio. However, for the few PSs obtained at the square, the increase of subsidence magnitude with the proximity to the river was verified. Two PSs presenting high subsidence rates were identified in buildings (red circumferences in Fig. 8) with velocities of $-9.8 \mathrm{~mm} / \mathrm{yr}$ and $-6.3 \mathrm{~mm} / \mathrm{yr}$. Collaboration with the Lisbon City Council has been established in order to obtain information about the identified buildings, but an answer was not achieved yet.

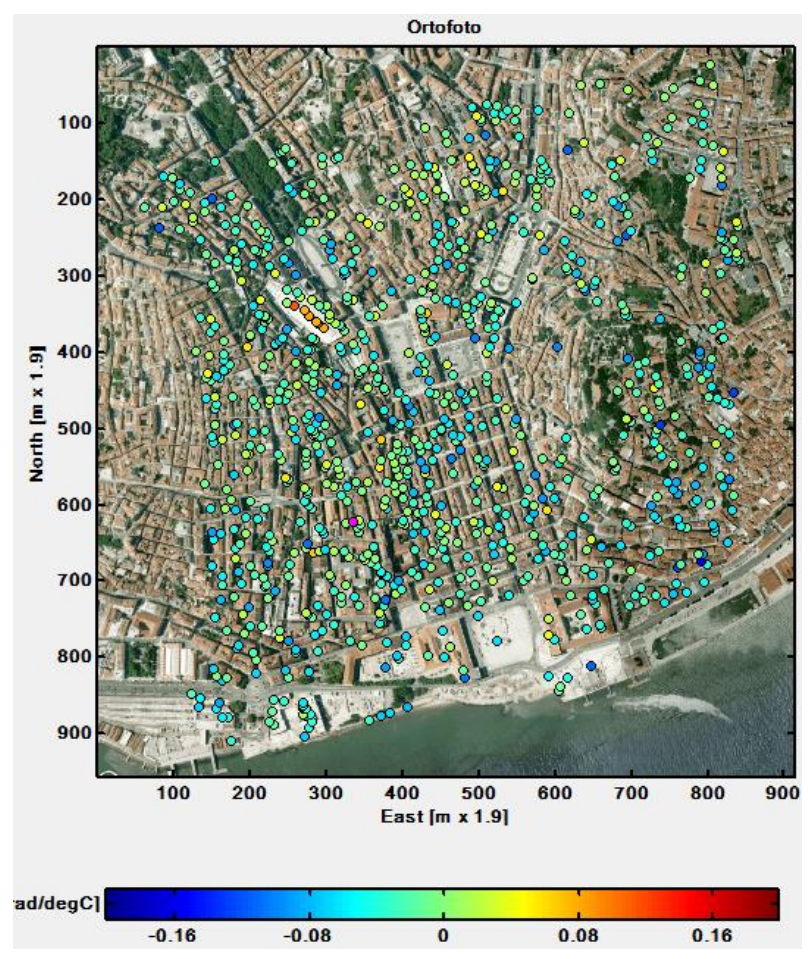

Figure 9. Ratio between phase and temperature for PSs located in the Downtown

Two seasonal trends were identified for the Downtown PSs (Fig. 9). Some of the PSs get closer to the sensor in summer and farther in winter. This behaviour is consistent to thermal expansion and is more evident for PSs located in metallic roofs. The highest values of the ratio between phase and temperature were verified for the Rossio train station (Fig. 10), which is the main station of the railway line connecting Lisbon to Sintra, one of the most used in the country. 


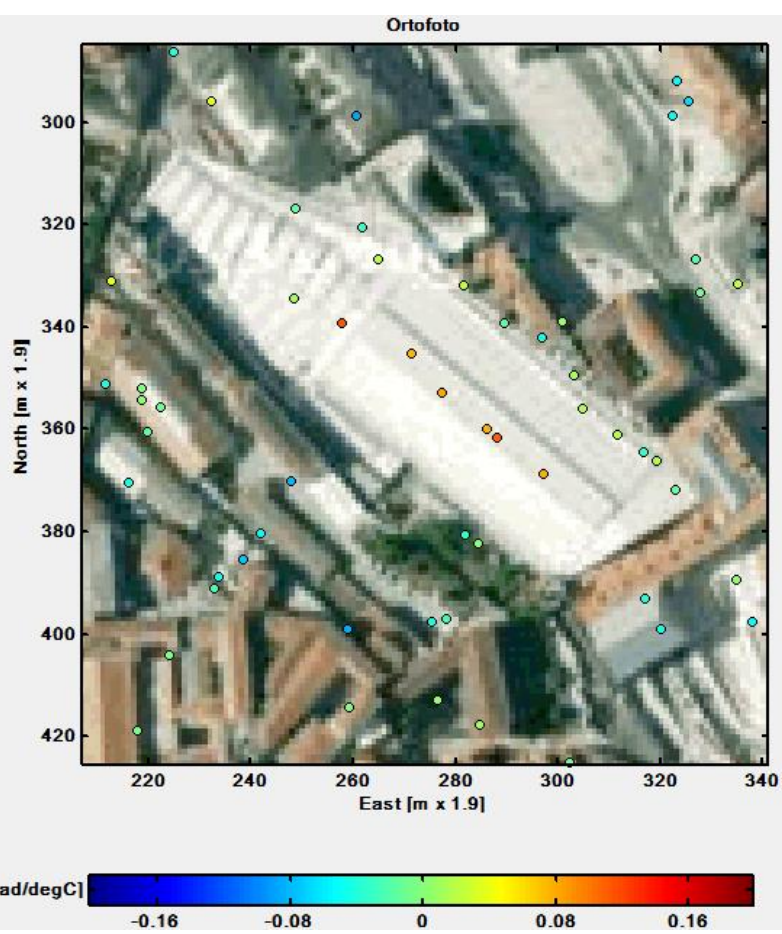

Figure 10. Ratio between phase and temperature for PSs located in the metallic roof of Rossio train station

Nevertheless, most points present the opposite behaviour, in which they get closer to the sensor in winter and farther in summer. There may be many causes for this trend, such as tidal loading or aquifer recharge that will be researched in future work. In order to identify any spatial patterns occurring in the data, two additional variables were determined using GIS tools: for each PS the distance to the river and the distance to the underground streams were determined. A Principal Component Analysis (PCA) was performed considering only the PSs with temporal coherence higher than 0.95 as samples and the many variables associated to them: cumulative displacement, linear velocity, height, residual height, ratio between phase and temperature, temporal coherence, distance to the river and distance to the underground streams. A high correlation was observed for the ratio between phase and temperature and the residual height. This correlation suggests that PSs may present a different seasonal behaviour whether they are located in buildings or in the ground. In fact, the time-series of PSs in buildings were verified to present behaviour consistent to thermal expansion, while those in the ground get closer to the sensor in winter, which is probably related to the presence of underground water. As the PS displacements observed in buildings are the sum of the displacements of the ground with those from the building, this behaviour is not always obvious.

\subsection{The MEO Arena building}

A small number of PSs was identified on the roof of
Atlântico room of the MEO Arena building. Five PSs were obtained in the easternmost part of the building and one in its middle. All PSs present a positive linear velocity, meaning that they are getting closer to the sensor (Fig. 11).

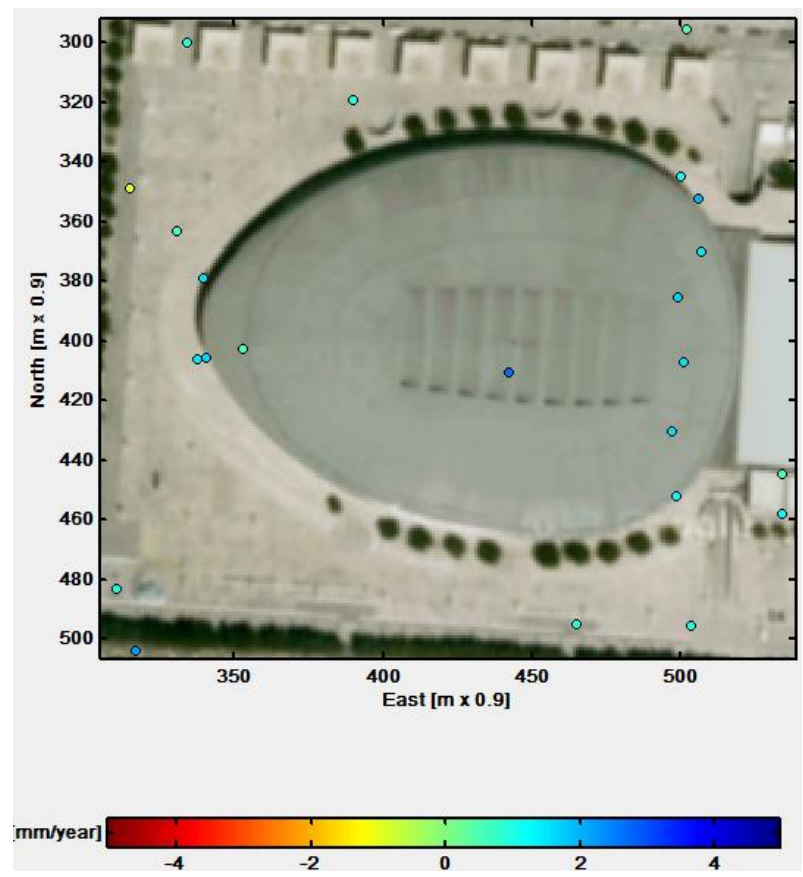

Figure 11. Linear velocity for PSs in MEO Arena building

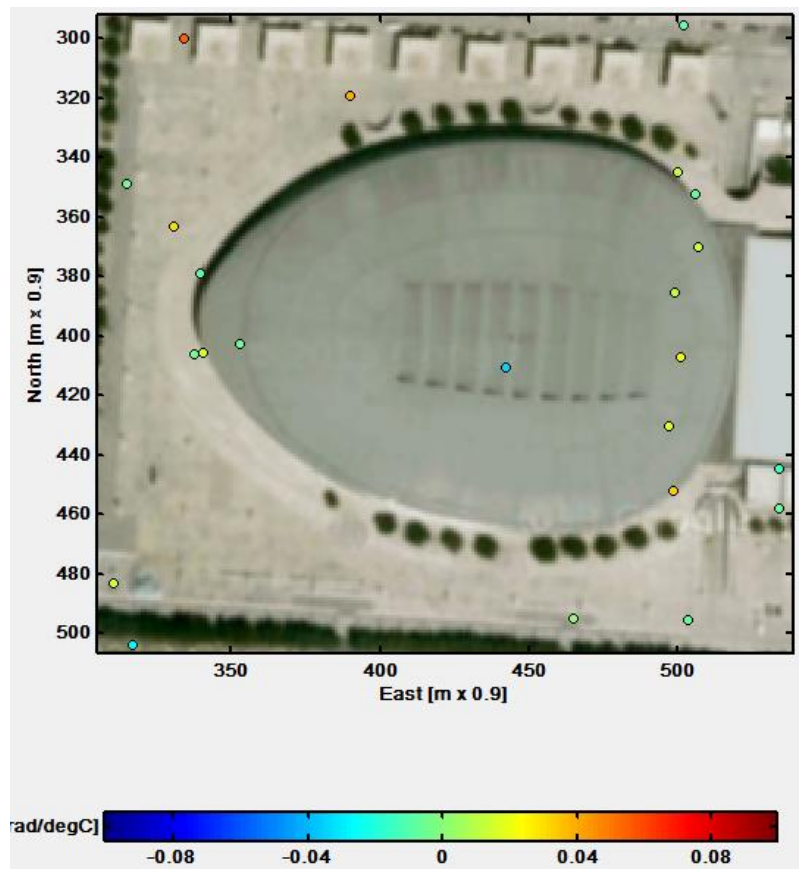

Figure 12. Ratio between phase and temperature for $P S$ s in MEO Arena building

As for the estimated seasonal trends, distinct behaviours were observed for PSs in different locations (Fig. 12). 
PSs in the easternmost part of the building present positive values of the ratio between phase and temperature, which is consistent with the thermal expansion of the roof. However, the PS in the middle has negative values of the same variable, going up in winter and down in summer. This PS is located above one of the points in the inner wooden arches surveyed by the National Laboratory for Civil Engineering. The fact that the PS rises in winter and goes down in summer may be explained by the transmission of the displacements from the inner wooden arches to the roof. The MEO Arena building is surveyed through geodetic techniques twice every year, in March and September. An analytic model was developed for the structure behaviour from those observations and displacement values for the acquisition dates of the SAR images were determined. The displacements of the targets attached to the wooden arches are determined with respect to two reference points located in the ground. In order to compare the results from MTI techniques to those from the geodetic measurements, the displacements obtained through MTI were determined with respect to a PS located in the ground close to the building. Similar oscillating behaviours were detected for the two points (Fig. 13), both of them presenting a period of one year. However, the amplitude of the displacements was smaller for the point observed with MTI. As the metallic roof takes direct sunlight, its temperature is higher than that of the wood inside the building; therefore, the roof thermal expansion may decrease the amplitude of the roof displacements caused by the wooden arches.

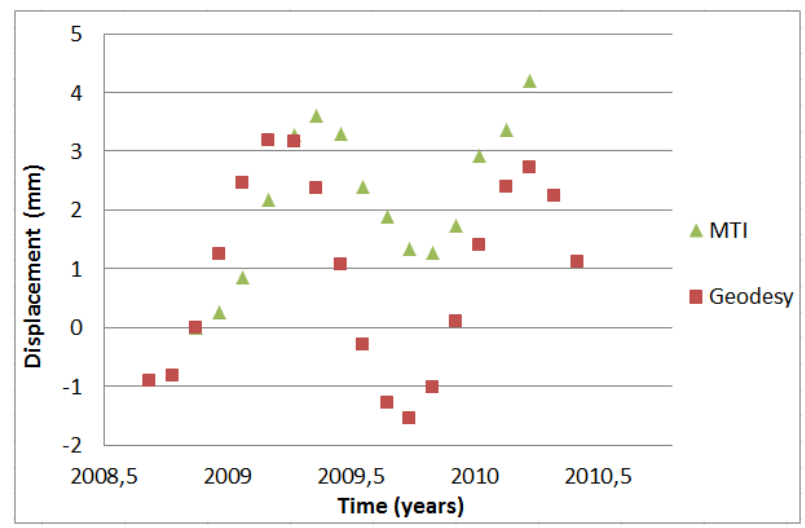

Figure 13. Displacement time-series for a PS in the roof determined through MTI and for a point in the inner structure determined through tacheometry

\subsection{The railway}

A high number of PSs was obtained for the considered study area and some of them show that the railway is located in unstable regions (Fig.14), particularly, an area in the west, named Oeiras, and another in the east, named Belém. From the 2855 PSs obtained for the whole study area, only 80 were located in the railway. Velocities reaching $-4.1 \mathrm{~mm} / \mathrm{yr}$ and $-3.2 \mathrm{~mm} / \mathrm{yr}$ were found for Oeiras and Belém, respectively. Analysing the time-series of the PSs in railway at Belém area, a seasonal pattern was identified, as most of the points get closer to the sensor in the summer and farther in winter. As for the Oeiras area, not all the points present the same behaviour. However, most of them also show a seasonal trend, in which the PSs get closer to the sensor in winter and farther in summer (Fig. 15). Causes for these phenomena are still being researched.

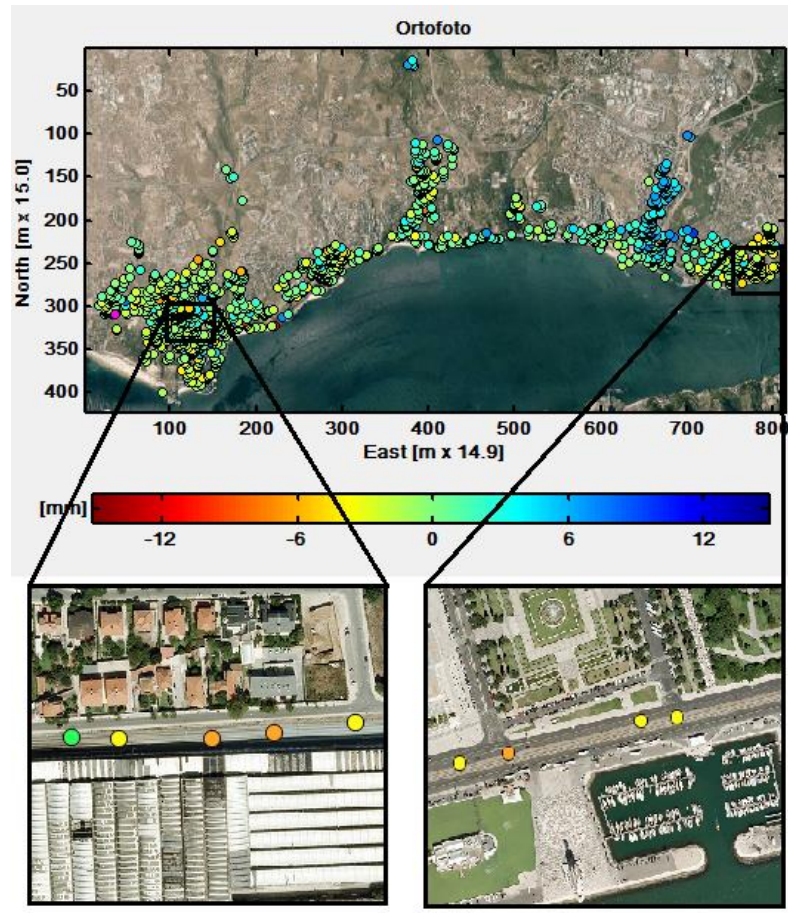

Figure 14. Cumulative displacement for study area (top); for Oeiras (bottom left) and Belém (bottom right)

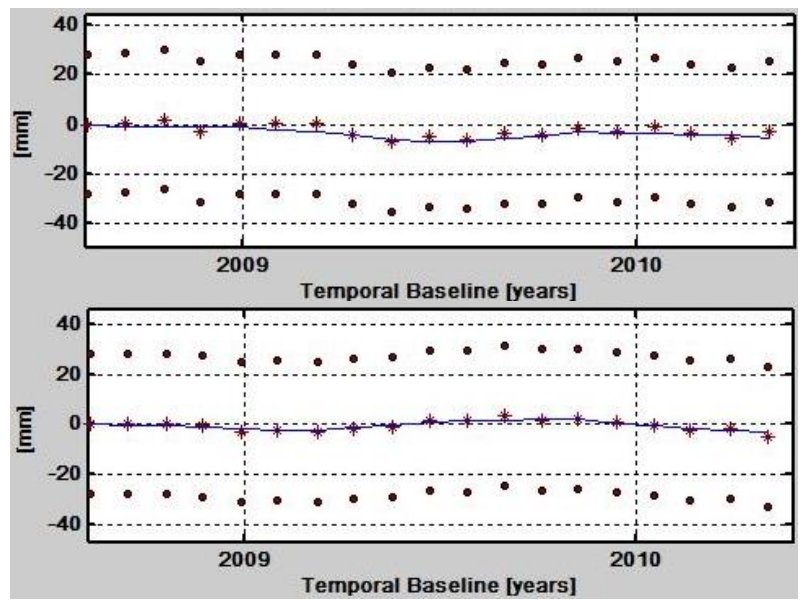

Figure 15. Displacement time-series for PSs in the railway for Oeiras (top) and Belém (bottom) 


\section{CONCLUSIONS}

The available dataset of Envisat ASAR images allowed a displacement regional analysis for the Lisbon municipality and its surroundings. A large area was found to present subsiding behaviour. However, the lack of PSs coincident to marks from geodetic networks in the city prevented the validation of the results. An area presenting high subsidence rates was identified in the town Póvoa de Santa Iria, close to an industrial park. The causes for that behaviour will be researched in future work. The refined processing for the city Downtown revealed instability in landfill areas close to the river reaching a maximum of $12.2 \mathrm{~mm} / \mathrm{yr}$ of subsidence rate and two buildings were verified to present signs of instability. Seasonal trends were also identified, namely behaviour possibly related to the presence of underground water, which is masked with thermal expansion for PSs located on buildings. Instabilities were not found for the MEO Arena building and MTI techniques were able to detect the seasonal behaviour observed with the geodetic techniques. Two instable areas were identified in the railway connecting Lisbon to Cascais. Seasonal trends were superimposed on the subsiding behaviour and their causes will be researched in future work.

For future work, the team intends to improve the presented analysis using Sentinel-1 data. The availability of larger time-series of SAR images, acquired at a regular frequency, and with a higher spatial and temporal resolution will enable an increased density of PSs and a better evaluation of the identified seasonal trends. Besides, the usage of these data would also allow the validation of the results, since the acquisition of geodetic measurements contemporary of the images would become possible.

\section{ACKNOWLEDGEMENTS}

Data provided by ESA.

\section{REFERENCES}

1. Roque, D., Fonseca, A.M., Henriques, M.J. \& Falcão, A.P. (2014). A first approach for displacement analysis in Lisbon Downtown using PS-InSAR. Procedia Technology, 16, pp. 288 - 293. doi: 10.1016/j.protcy.2014.10.094.

2. Osmanoglu, B., Dixon, T.H., Wdowinski, S., CabralCano, E. \& Jiang, Y. (2011). Mexico City subsidence observed with persistent scatterer InSAR. International Journal of Applied Earth Observation and Geoinformation, Vol. 13, No. 1, pp. 1-12.

3. Perissin, D. \& Wang, T. (2011). Time-series InSAR applications over urban areas in China. IEEE Journal of Selected Topics in Applied Earth Observations and Remote Sensing, Vol. 4, No. 1, pp. $92-100$.
4. Zhang, L., Lu, Z., Ding, X., Jung, H., Feng, G. \& Lee, C.-W. (2012). Mapping ground surface deformation using temporarily coherent point SAR interferometry: Application to Los Angeles Basin. Remote Sensing of Environment, 117, pp. $429-$ 439. doi:10.1016/j.rse.2011.10.020.

5. Frattini, P., Crosta, G.B. \& Allievi, J. (2013). Damage to buildings in large slope rock instabilities monitored with the PSInSAR ${ }^{\mathrm{TM}}$ technique. Remote Sensing, 5, pp. 4753 - 4773. doi: 10.3390/rs5104753.

6. Gernhardt, S. \& Bamler, R. (2010). Towards deformation monitoring of single buildings persistent scatterer interferometry using TerraSAR-X very high resolution spotlight data. In Proc. of EUSAR 2010, VDE VERLAG GMBH, Berlin, Offenbach, pp. $1138-1141$.

7. Heleno, S.I.N., Oliveira, L.G.S., Henriques, M.J., Falcão, A.P., Lima, J.N.P., Cooksley, G., Ferretti, A., Fonseca, A.M., Lobo-Ferreira, J.P. \& Fonseca, J.F.B.D. (2011). Persistent scatterers interferometry detects and measures ground subsidence in Lisbon. Remote Sensing of Environment 01/2011; 115(8): 2152-2167. doi:10.1016/j.rse.2011.04.021. 